\title{
Internal Mechanisms Framework of Lean Implementation using the Visual Management Systems
}

\author{
Koichi Murata ${ }^{1}$ \\ ${ }^{1}$ Department of Industrial Engineering and Management, College of Industrial Technology, Nihon University, Chiba, Japan.
}

ABSTRACT - This paper proposes a theoretical framework of the internal mechanisms of a visual management system, which is one of the main schemes of lean management. The research method designs with Design Science Research which complements theory and practice. For theoretical side, the relevant tools are described using the graphical block diagram from control theory. For practical side, the implementation of the initial trial in this paper is also aimed at systematic design through the perspective of the proposed framework by collaborating with a chemical plant in proceeding with safety and effective operations. As the results, the control theory, which is one of the robust theories that strengthens the academic approach on visual management, is also used to develop the proposed framework. In the originality, this paper focuses on the internal mechanisms of the visual management system and implicates a representation of general system specifications and the possibility of diverse system development in an effort to better understand and improve such a system.
ARTICLE HISTORY

Received: 05-11-2020

Accepted: 03-01-2021

\section{KEYWORDS}

Lean management

Visual management

Theoretical framework

Control theory

Design science research

\section{INTRODUCTION}

With regard to visual management that represents a means for solving various problems in a production system within the scheme of lean management (Ohno, 1988, Womack et al., 2003, Liker, 2004), practitioner's activities have exceeded academic research activities. Beynon-Davies et al. (2017) speculated three reasons for this phenomenon. First, over the past two decades, publications that promulgate visual management are heavily associated with management consultancy in the practice of lean management. Second, the principles established for visual management are mostly based on anecdotal cases of good practice, rather than on some foundations established in academic theorizing, which open up avenues of empirical investigation. Third, visual management systems has not been examined in any real detail by cognate fields, such as operations management and information systems.

It is contended that in the background of the aforementioned reasons, the following characteristics of visual management play a role. A visual artifact in a workplace is extremely easy to understand. It operates based on the sense of sight, which is the most useful of the five senses to use for information gathering. The main function of the artifact is the identification of a message at a glance beyond the perceptive limitation of consciousness and attention (Rees et al. 1999, Simons et al., 1998, Simons et al., 1999). A good practice plainly and directly conveys a message to lead to fast decision-making and quick reaction, which is increasingly important when companies encounter various risks in globalizing their activities (Zsidisin et al., 2005). A visual workplace also has an extraordinary variety of elemental technologies to manage various purposes, such as production management, quality control, information sharing, and team communication (Greif, 1991, Cahyadi, et al., 2020). Furthermore, the "visual factory" (Greif, 1991) is an innovative concept that extends the application of visual management tools from the production function to other corporate functions, including administration, engineering, and sales. Parry et al. (2006) reported that these are powerful tools that can be used beyond manufacturing. Recently, lean construction has been confirmed as an extended application of lean management in the production sector (Sacks, et al. 2010). Further, visual management systems are considered as one of the basic support methods for lean construction (Tezel, et al. 2016). Tezel, et al. (2016) classifies the relevant systems in the construction sector in Brazil. Valente, et al. (2017) also develops the guidelines for devising and assessing visual management systems based on a survey with interviews of several construction sites. Another reason for the extended application of the visual systems is that it contributes to the maintenance and improvement of the relevant key performance indicators (KPIs), such as reliability, productivity, and safety (Dumitrascu, et al. 2020).

The utility of visual management is evident from the above-mentioned discussion. Therefore, systematizing the study on visual management for addressing theoretical rules and principles appears to be extremely important. In order to better explore the visual management system involving a tool, this paper proposes the application of a graphical block diagram from control theory (Iqbal, et al. 2010), which has been widely known in mechanical engineering, inventory management, and supply chain management (Spiegler, et al. 2017, Dolgui, et al. 2018, Wu, et al. 2020).

This paper aims at presenting an anatomy of the visual system, explaining the following: 1) the relationship between a visual management system and the production system managed by means of it;2) the internal mechanism of a visual 
management system and its capabilities; and 3) the metrics that measure the right performance of the system to realize visual management.

In order to realize these purposes, this paper proposes a framework to explore the internal mechanisms of a visual management system using control theory. The proposed framework provides the components around the visual management tool and the transactions on the relationships among and including the tool. Using the framework which includes the novelty of this paper has the potential benefit to understand a visual management system in the production/manufacturing companies. Because the framework should give production managers the perspectives of the effective management of a tool's lifecycle, such as an analysis of a worksite to install a tool, insight into an installed tool's role and function, and the design of a new tool.

This paper is organized into seven sections. The relevant prior literature on visual management tools and the control theory utilized for the proposed framework is reviewed in the second section. Third section illustrates the research procedure in this paper. In the fourth, the framework of a visual management system is proposed. The development of a visual management system in a chemical plant is described in the fifth section. In the sixth section, the utility of the proposed framework is discussed on the basis of the development process and results in the fifth section. The seventh section concludes the paper.

\section{LITERATURE REVIEW}

This section reviews the visual management tool, which is the main component of the proposed framework described in the following section, and control theory that is applied in the development of that framework.

\section{Visual management tool}

At the time when researchers recognized a visual management tool in the studies on the Toyota Production System (Spear, et al. 1999, Sisson, et al. 2015), there were many publications on management of manufacturing operations. The observant explorations of excellent visual management tools resulted in new concepts, such as visual factory (Greif, 1991) and visual communication (Mestre et al., 2000), which include many classified tools, such as visual indicator, visual signal, visual workplace, visual devices, visual guarantees, and visual standards (Galsworth, 1997). These advances in the manufacturing industry have positively been applied to the practical operations in different fields, while the systematic transfer of visual management tools has developed on the academic side (Murata et al., 2010a, Murata et al., 2010b, Murata et al., 2016). In recent publications, the application fields include the construction industry (Tjell et al., 2015, Tezel et al., 2017a, Singh et al., 2020), healthcare management (Verbano et al., 2017), medical laboratory industry (Isack et al., 2018), and small- and medium-sized enterprises (SMEs) (Fonseca, 2017, Laoha et al., 2016).

Focusing on a visual management tool, the incessant analysis of its practical cases leads to a deeper understanding of the tool and realizes its improvements. Murata et al. (2013) proposed a mathematical model to evaluate the tools' performance. Pató (2017) expanded the job description method, a fundamental tool for capturing operation transformation, in order to gain operational knowledge using both three-dimensional (3D) and two-dimensional (2D) techniques. Dashboards to visualize production planning and control were analysed by Brady et al. (2018). Performance management, utilized for sharing the current and future production system conditions among worksite members, was developed through the system science (Flumerfelt et al., 2017). Furthermore, owing to a new production paradigm (Koren, 2010), not only hand-made tools, but also advanced tools, have been continuously developed by information technology (IT), information communication technology (ICT), and the Internet of Things (IoT) (Sugawara et al., 1994, Fitrianie et al., 2007, Chen, 2020). Some industries already actively use new tools, such as building information modeling (BIM); mobile computing; augmented reality (AR); surface scans, including laser scanning; photogrammetry; and radiofrequency identification (RFID) (Steenkamp et al., 2017, Tezel et al., 2017b, Abou-Ibrahim et al., 2020).

The approaches addressed in the above mentioned studies are based on strong practices within a worksite and/or are supported by the new information communication technologies. However, beyond empirical investigations, researchers should offer a deeper understanding of the system involving a visual management tool to industry members through academic theorizing.

Regarding theoretical studies on a visual management tool combined by empirical studies, Tezel et al. (2016) and Bell et al. (2013) reveal future research topics based on literature reviews. Tezel et al. (2016) arranged themes for theoryfocused research: function and roles of visual management, visual management as organizational affordance, visual management and organizational socio-materiality, theoretical discussions on the concepts of visual management, visual workplace and visual tools, visual management research, visual studies perspective, workforce perception of visual management, and visual management tools as boundary objects across different social groups. Bell et al. (2013) picked up on the types of useful academic theories to systematize visual management theory, such as media richness, ethnographic study, organizational theory, knowledge management, and information science.

In fact, in the area of lean management where visual management is used, studies are already performed from the viewpoint of organizational culture (Paro et al., 2017), organizational psychology (Hozak et al., 2015), performance management (Eaidgah et al., 2016), and barriers for installing the scheme (Jadhav et al., 2014). Furthermore, regarding the advanced studies on the application of academic theories, Beynon-Davies et al. (2017) explores a visual tool in the health care industry using affordance theory. 


\section{Control theory}

Control theory is widely known across a broad range of both research and practical fields. According to Carver et al. (1982), control theory provided the central ideas to reveal homeostatic physiological mechanisms in the 1920s. One of the latest publications applicable to the theory is confirmed in the newest field of synthetic biology, which is an interdisciplinary branch of biology and engineering, including genetic engineering, nanotechnology, and biomechanics (Del et al., 2016). There has also been related literature in the area of operations management and supply chain management that often use visual management tools (Edghill et al., 1989, Ortega et al., 2004, Ivanov et al., 2012, Subramanian et al., 2013), including publications by Simon (1952), a winner of the Nobel Memorial Prize in Economic Sciences.

A production system involves dynamic and instable mechanisms that organize physical management resources, such as humans, machines, and materials. Each of these is not only a valuable means to satisfy customer requirements, but also a source of disturbances that lead to deviations in operations, wasted energy consumption, and quality complaints. A production system should contain an internal control structure to overcome the above problems.

Control theory aims to consider the relationship between a control system and the input/output relationship of the system managed by it. There are two main loop functions that are included in the theory. The first is the feedback-loop function, which is the negative feedback that an output returns to an input. When receiving feedback results, a system regulates an input and operates to minimize the difference between the next output's plan and result. The second is the feedforward-loop function, which performs the pre-detection of an occurrence of a disturbance against a system, and the pre-revision, before operating an input based on the pre-detection; it is a complementary operation that supports the feedback-loop function.

One of the useful tools in applying the theory involves the block diagram, which aims at drawing concept level representations for a system that includes a control function. The diagram involves simple graphical manipulations that may provide additional insight into the behavior of the system. The diagram essentially consists of three elements: 1) signals; 2) systems; and 3) summing junctions (Iqbal et al., 2010). In the proposed framework of this paper, a visual management system is the control function of a production system and is represented by the method of the block diagram as discussed in the following sections.

\section{RESEARCH METHOD}

This paper adopts Design Science Research (DSR) because this methodology has the ways in which theory-oriented academic research and problem-solving research can complement one another (Holmström et al., 2009). DRM advances to make novel theoretical insights and practical relevance complementary with enhancing the cross-fertilization between academic research and research practice. Followed by this procedure, this study consists of three parts as shown in Figure 1. The first part is a theoretical description of the visual management system. The internal structure of the visual management system is expressed using control theory. Then this part systematically derives the three components of the visual management system and the two functions to make their relationships, in addition, and explains the capabilities to establish the cooperation between the components with reference to related literature. The second part actually designs a visual management system. This is a tool development aimed at preventing basic operations in chemical plants that are actively installing visual management. Also, this part will evaluate the results based on the opinions of practitioners. The third part is a discussion of the visual management tool development process that is done in the second part, using the theoretical framework proposed in the first part. This part will examine the validity of the proposed theoretical framework to understand whether practical hints for better tool development can be systematically derived.

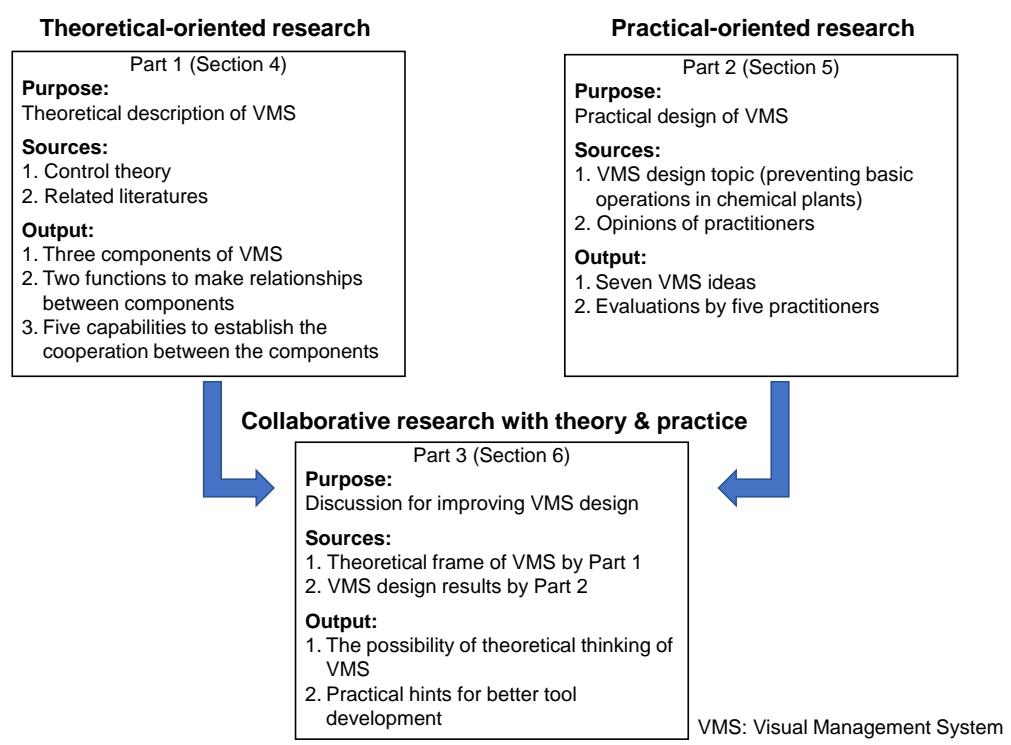

Figure 1. Research framework. 


\section{PROPOSED FRAMEWORK}

\section{A visual management system as the control function of a production system}

A visual management system is described through the block diagram shown in Figure 2. The optimum performance $\theta_{I}$ is the input data, the actual performance $\theta_{O}$ is the output data, and the difference between them $\varepsilon\left(=\theta_{I^{-}} \theta_{O}\right)$ is the error. Variations in management resources $\theta_{R}$ (humans, materials, machines, etc.) create disturbances to the production system $K_{l}$ as a controlled object. The visual management system $K_{2}$ determines a manipulated variable $\mu$ to minimize the difference $\varepsilon$. The variable $\mu$ is an input to the production system $K_{l}$.

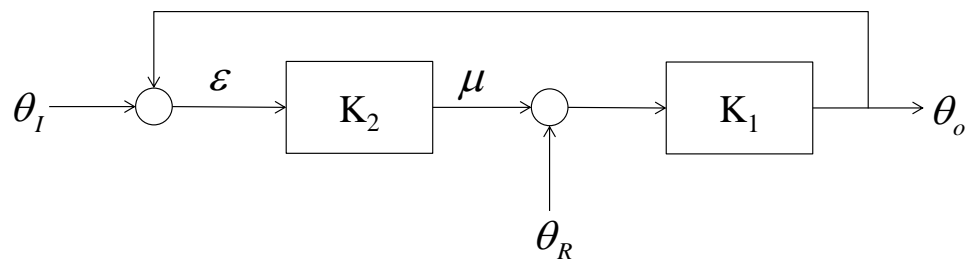

Figure 2. A production system $\left(K_{l}\right)$ with a visual management system $\left(K_{2}\right)$.

The analytical method used in this paper is demonstrated in Figure 3; it shows the internal visual management system $K_{2}$ in Figure 2. Within the framework, visual management systems are thought of as tools that support communication between people and the production systems they manage. The framework has three components: 1) people as receivers of error information $\alpha$ and executors of $\mu ; 2$ ) the production system $K_{l}$ managed by people; and 3) a tool to realize visual management. This framework aims to represent two key items: 1) a reaction $\mu$ requested by the production system from the people; and 2) functions of the tool.

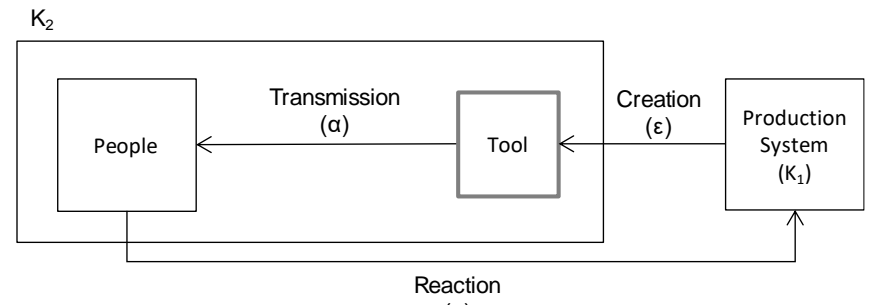

(u)

Figure 3. The basic mechanism of a visual management system.

\section{Capabilities of a visual management system}

In the proposed framework, the following five capabilities are suggested to be vital for a visual management system. The illustration of these capabilities is followed by the above-referenced two key items as discussed in the next two subsections.

\section{Comprehensibility \\ 2. Non-ordinariness \\ 3. Continuity \\ 4. Inducibility \\ 5. Timeliness}

For the first key item, the reaction $\mu$ is action by people requested by the production system when it fails. The comprehensibility (first capability) and the level of expertise and/or experience of people and organizations, of which the relationship seems to be a trade-off (as presented in Figure 4; originating in this study), need to be considered thoroughly. The relationship has been continued to be studied as the problem of expert-beginner difference (De et al., 1996) from various perspectives; the analysis and clarification of this difference (Wang et al., 2015, Zhou, 2016), the measurement and evaluation of tacit knowledge and skills (Verner et al., 2003, Tervo et al., 2009), and the technology development for the coexistence of experts and beginners (Zia et al., 2018). Recently, the competition between companies offering products in the world market has become fiercer, providing a background for this relationship. An immediate asset, such as a skillful worker, is a powerful weapon that can contribute to the company survival in a difficult business environment. On the other hand, as experience in human resources training invariantly shows, there are necessary processes for someone to become a respectable member in a production setting. When a new member comes into the workplace, appropriate support must be provided to operate a production system without trouble. In order to correspond to the contradiction of such situations, production members should systematically develop the reaction while they ascertain the new member's problem-solving ability and the reasonable speed of the development of their production performance. 


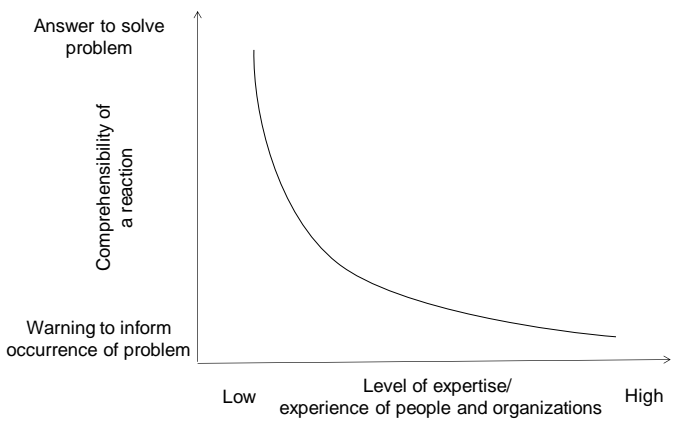

Figure 4. Relationship between expertise and/or experience level and comprehensibility of a reaction.

For the second key item, two functions of a tool, namely creation of information $\varepsilon$ and transmission of information $\alpha$, need to be designed. These are based on the two principal questions of the breakthrough innovations (Stefik et al., 2004): 1) "What is needed?" concerns operation, business, and social needs; and 2) "What is possible?" concerns research, discovery, and invention. When discussing the two functions, the two questions are respectively rearranged to "What do you see next?" and "How do you design a device to attract attention?"

In the first function, a visualized item is developed by a production system and is sent from the system to a tool. When designing this function, the non-ordinariness (second capability) and continuity (third capability) of the created information need to be considered.

Non-ordinariness needs to be designed to determine when a visualized item has to be created. When the production system is in the ordinary condition, the tool is not required to work. The important role of this tool is to completely handle the complicated statuses that arise within the production system from the four directions obtained from the two sources discussed below. Taiichi Ohno, the founder of Toyota production system (TPS), including the two representative visual management tools Andon and Kanban, characterized these devices as follows:

This clarifies what is normal and what is abnormal (Ohno, 1988).

The advocates of lean management James P. Womack and Daniel T. Jones, who conceptualized lean taking the TPS as a starting point, expanded Ohno's definition as follows:

The placement in plain view of all tools, parts, production activities, and indicators of production system performance, so the status of the system can be understood at a glance by every involved. Used synonymously with transparency (Womack et al., 2003).

Womack's definition gives four clear understandings of a visualized item on the basis of Ohno's one. The first is the richness of objects where an abnormal status quietly hides; examples include tools, parts, production activities, and indicators of production system performance. They are the objects that are the root resources regarding which wastes must be detected to decrease the abnormal status of a production system.

The second is the multiplicity of performance indicators, one of the above-managed objects, which gives the viewpoints to monitor a production system. The quality of a product, the lead time, including production, delivery and service functions, and the costs related to these functions, are recognized as the indicators to continuously evaluate performance of the production activities. The other qualitative indicators developed until now, and from now on, each contain both normal and abnormal conditions. PDCA-cycle management of all indicators is necessary to strengthen the continuous improvement of the production system performance.

The third is regarding the meaning of "abnormal." An abnormal status usually represents a "bad" status. However, if an abnormal status is considered as the "special" status, which is different from the daily status, the meaning of the status is not always a "bad" status, but can also be a "good" status. When observing some worksites, many tools have actually been found to praise and invigorate daily production activities. Both statuses need to be considered when discussing a visualized item.

The fourth is the problem-solving process. Following Ohno's definition, a visualized item is originally for the early detection of an abnormal status in order to start thinking past the problem activity. In this instance, Womack's perspective is not only utilized for the initial step of problem-solving, but also for finding loss or waste in a production system, and exploring and identifying the causes, predicting the impact induced by the aggravation of the problem, designing the countermeasures, and confirming the utility of the designed and installed countermeasures. In the above-mentioned Womack's definition, transparency is needed in all steps involved in the problem-solving process. A visualized item should be selected according to the stage within that process.

With regard to continuity (third capability), the tool must have a structure to monitor the typical conditions of the production system in order to grasp special situations at any time as they arise. As the social background, industries encounter various risks when globalizing their activities (Zsidisin, 2005). The risks can be divided into internal and external risks. The former risks such as loss of perishable supplies, mistaken operation, contamination, strike, and violation of rules has been managed conventionally. However, the impact of customer complaints and incidents of 
environmental destruction are becoming larger than before with the expansion of social responsibility of companies (Istanbulluoglu, 2017, Oliva et al., 2018). The latter risks such as a health epidemic, natural disaster and terrorism (also in the form of cyberterrorism) have been born anew in the present age. Their destructive power includes the possibility to bring a fire in a factory and to stop industrial infrastructure networks (Hohenstein et al., 2015, Carbonara et al., 2017). Due to the recent situation of risk diversity, the importance of continuous risk monitoring is recognized more than ever before.

For example, a progress chart, a handmade visual management tool, is used as a typical tool for daily communication in order to present the project plan, ascertain whether it has progressed as scheduled or not, and re-schedule it if there is a delay (Tezel et al., 2018). With regard to the capability of continuity, observations have mainly found that the design procedure involves two selection steps. The first selection is how to create a progress chart as the base to comprehensively manage a project on a worksite. One option is an object drawn directly on a whiteboard; another option is an object printed from a scheduling software. The initial design of the former, and its continuous customization, is definitely laxer than the latter, of which the format is fixed, but which is easy to print. Next, a whiteboard for a to-do list is added to a progress chart in the second selection. The discussion of prompt action with direct-writing on the to-do list is considered efficient management with a process chart. The addition of an application rule of the whiteboard, including colored notes and/or colorful marker pens that are also useful to promote problem-solving, is necessary to continuously prevent its degeneration.

In the second function, the visualized and created items are provided from the tool to a manager or an operator. When designing this function, the inducibility (fourth capability) and timeliness (fifth capability) of the delivery of the visualized item need to be considered.

Inducibility refers to the relationship between an operator and a tool. In the area of physiology of the operators, inattentional blindness and change blindness are key technical terms related to a human's perceptive function of consciousness and attention. The former indicates that an observer may not even perceive objects without attention (Rees et al. 1999, Simons et al., 1999). The latter refers to a situation where an observer lacks a precise visual representation of their world, from one view to the next (Simons et al., 1998). These behaviors indicate the possibility of a production control failure, even if a visual management system is installed. As for a tool, its long-term use may have the possibility to gradually lose the original value of the tool. Wasteful and unessential tools have been observed in some worksites owing to the shortcomings in their management. Such a loss of the tool is explained in the following example (Murata et al., 2008). Occasionally, operators may not identify the true visualized item because the item visualized by a tool is not directly connected to the changeable occurrence cause of the abnormal condition. Also, there have been cases where a tool's layout is not considered; however, a tool must be utilized naturally in relevant operations, if at all possible. In other cases, maintenance shortages and/or shortages of the lifecycle management of installed tools have been observed. For example, tools, such as several posters that share the same purpose, might be set up at the same place, and a neglected posted notice might start to peel off. In order to overcome this, a tool needs to continue to have appeal for operators by maintaining the capability of inducibility of the tool over its lifecycle.

With regard to timeliness, the delivery timing of the created visualized item has to be as soon as possible when an immediate reaction is required to the prevailing condition of a production system. In the TPS, there is the following way of thinking regarding this capability:

Too much information induces them to produce ahead and can also cause a mix-up in sequence. Items might not be produced when needed, or too many might be made, some with defects. Eventually, it becomes impossible to make a simple change in the production schedule (Ohno, 1988).

Even if a tool creates the smart visualized item and shows it with high inducibility, bad timing to inform through the tool may induce an opportunity loss to recover a production performance. For example, in a factory, often communication occurs among managers, staff, and operators, who work at different locations and/or in different times. In other examples, multi-site production planning to survive in the era of diversification of customers' needs is executed at the same time and in the same and/or different locations. Many different specialists, such as a mechanical engineer, a quality manager, and a line manager, join one production planning effort according to the progress. The communication based on the above conditions is naturally difficult, but remains necessary for smooth operation, accurate job and safety management, localresident care, and speedy decision-making.

The next section introduces a case on the development of a visual management tool and discusses its capability utilized by the proposed framework.

\section{RESULT}

\section{The problem to be solved}

This section describes a case involving the development of visual management tools, focusing on one small problem. The problem is referred to as the "twin-switch problem" shown in Figure 5. The two switches are used to operate different pieces of equipment, but the format of the two switches is quite similar and they have been installed close to each other. Therefore, there is a considerable probability of operating the wrong switch. The occurrence of a mistake in operation may possibly cause mass disposal of products, and the plant may need to be stopped. Generally, in a chemical plant equipped with a highly automated operation system, control operations are realized through a distributed control system 
(DCS), which is configured from a set of autonomous controllers (Barenji, 2014). However, some operations are performed by hand due to considerations related to the cost-effectiveness of investment in plant/equipment and the necessity of a visual confirmation. Moreover, according to the industrial engineers who work at the company addressed in this case study, there are many similar situations everywhere in a chemical plant, and there is one case with several twin-switches lined up in the same place. The twin-switch problem has become a typical problem in such cases and it is necessary to understand how to prevent related operational mistakes by workers. In reality, this operation is performed by two operators; however, in this section, the instance where this operation is performed by only one operator is addressed for the sake of simplicity.

The following three conditions exist in the development of the solution: 1) one switch cannot be separated from the other switch; 2) a large investment for a big re-installation of the switches cannot be performed; and 3) a visual management system is applied to resolve the problem.

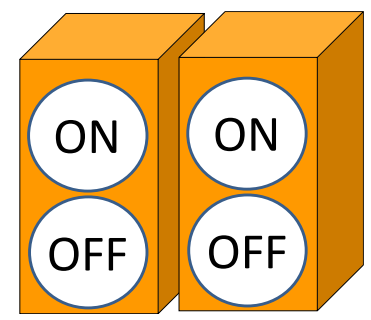

Figure 5. Twin-switch problem.

\section{Development of a visual management tool}

Developing a visual management tool is a four-step process: 1) analyze the processes of the target operation; 2) consider the visualized item for each analyzed process; 3) conceptualize the tool for each visualized item; and 4) design a tool for each visualized item. The outputs of each step are 'process', 'visualized item', 'concept', and 'tool image of each concept' as shown in Figure 6.

In order to consider the items visualized by the tool in step 1, a simple motion study is used to disassemble some motions of the operation sequence for designing more suitable concepts. As a result of the study, four sub-operations are identified: 1) stand in front of the switches; 2) select a switch; 3) press the selected switch; and 4) confirm the intended equipment operating.

In step 2, visual items are developed in each sub-operation. This is not difficult given that there is only one managed object in each sub-operation. The existence of the point to note is one visualized item for the first sub-operation: the correct switch box is one visualized item for the second sub-operation; the correct button of the switch is one visualized item for the third sub-operation; and, the correct operation is one visualized item for the fourth sub-operation.

Steps 3 and 4 are performed through free discussion and collaboration with plant experts by using KJ method, developed by Jiro Kawakita (Scupin, 1997). This method has been widely recognized as a useful creative team brainstorming technique to gather qualitative data. In step 3, concepts are developed for each of the four visualized items: a) Reflection and b) Prediction are two concepts for the first sub-operation; c) Differentiation and d) Unification are two concepts for the second sub-operation; e) Procedure and f) Double-check are two concepts for the third sub-operation; and g) Post-confirmation is a concept for the fourth sub-operation. These seven concepts are illustrated as follows:

a) Reflection: In this concept, a worker can recognize the possibility of an erroneous operation by recalling past cases, and displaying the defect and the situation that occurred in a previous accident near the switches.

b) Prediction: In this concept, a worker can recognize the operation that is in need of caution by displaying bulletins against the background of a heterogeneous state, such as a beautiful landscape and magnificent view, as well as displaying the phases and tables to awaken caution.

c) Differentiation: The point of the similarity between two switches is resolved by the visual differences between them. The purpose of this concept is to make two switches quite different. If the similarity between them remains after installing this concept, the possibility of an error is still present.

d) Unification: In this concept, the mechanism that operates the two switches can be realized by the development of one simple operation. It will help a worker to select which switch to operate without the confusion from the similarity between the two switches.

e) Procedure: In this concept, two switches are regarded as one system. The system provides the order of a series of operations to a worker.

g) Double-check: In this concept, two switches are regarded as one system. The system provides the information to confirm the correct order of steps a worker performs.

h) Post-confirmation: In this concept, a worker can check the equipment state by the display developed after a worker operates. 6.

In the final step, these concepts are embodied in the images of the tool, followed by the illustration as shown in Figure 


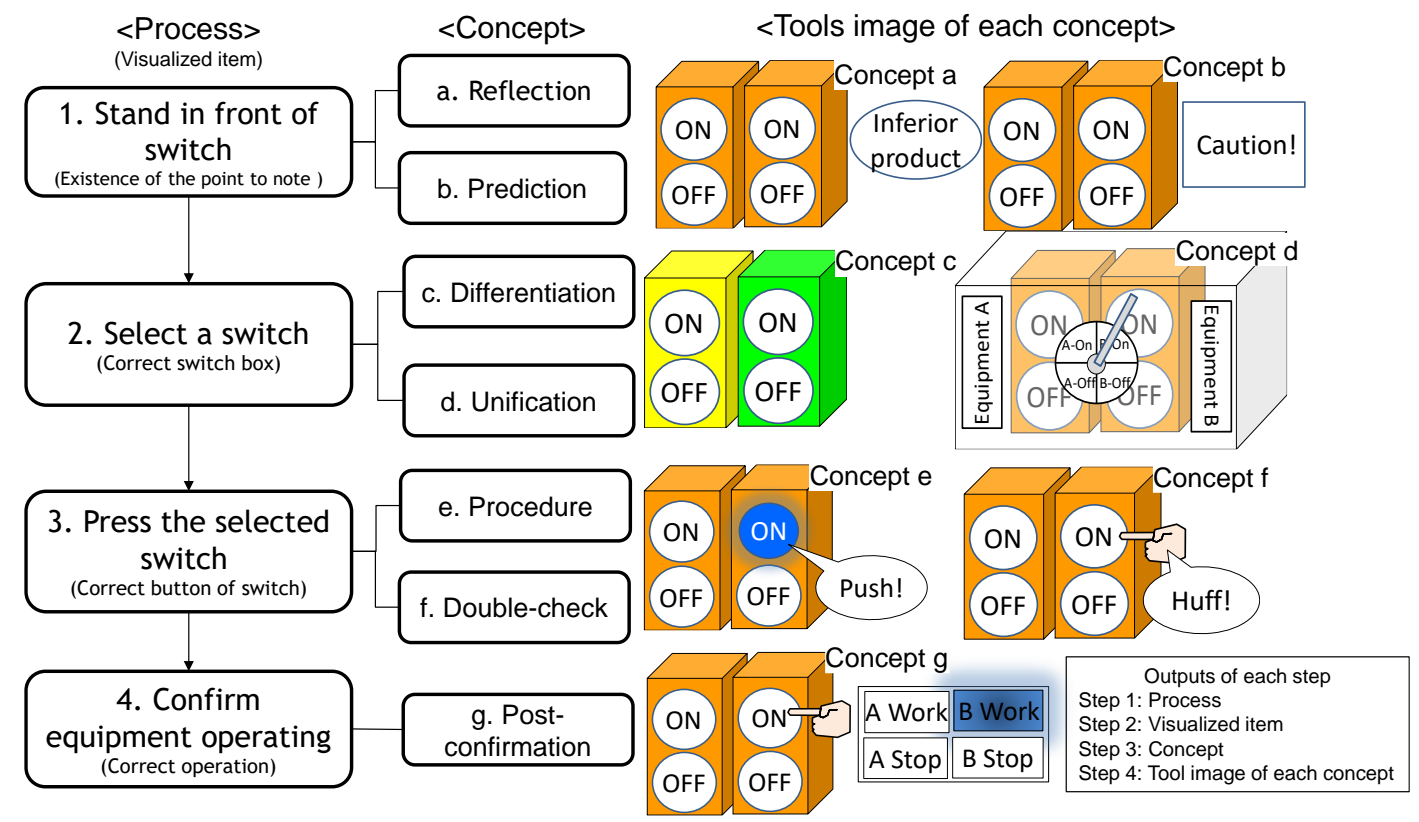

Figure 6. Design tool results for the twin-switch problem.

\section{Evaluation of developed tools}

This section evaluates the results of the developments discussed in privious section. The practical evaluation standard of the capability of the developed concept is established from two viewpoints, usefulness and ease of installation. The first viewpoint has two sub-standards: 1) the expectation to prevent accidental operation through the developed concept (Do you expect that an operational mistake is prevented through the use of the developed concept?); and 2) the durability of the effect of the developed concept (How long is the effect of the developed concept?). The second viewpoint has two sub-standards: 1) the development economics of the developed concept (What is the cost and time needed for installing the developed concept?); and 2) the reconstruction degree of the installation of the developed concept (What is the degree of reconstruction from the current device to the new device after remodeling?).

In order to evaluate these using two viewpoints, two formulas were created as follows using a five point scale:

$$
e 1_{h}=\sum_{i=1}^{m} s_{i} c_{h i}(h=1, \ldots, l)
$$

(Evaluation formula for the usefulness of each concept)

$$
e 2_{h}=\sum_{j=1}^{n} t_{j} c_{h j}(h=1, \ldots, l)
$$

(Evaluation formula for the ease of installation of each concept)

$e 1_{h}:$ Score of usefulness of developed concepts

$e 2_{h} \quad$ : Score of easiness of developed concepts

$s_{i} \quad$ : Weight of evaluation standard $i$ of usefulness of developed concepts

$t_{j} \quad$ : Weight of evaluation standard $j$ of easiness of developed concepts

$c_{h i} \quad$ : Evaluation results of evaluation standard $i$ of developed concept $h$

$c_{h j} \quad$ : Evaluation results of evaluation standard $j$ of developed concept $h$

$l \quad$ : Number of concepts

$m$ : Number of evaluation standard of usefulness of developed concepts

$n \quad$ : Number of evaluation standard of easiness of developed concepts

$h \quad$ : Suffix of a concept

$i \quad$ : Suffix of an evaluation standard of usefulness of developed concepts

$j \quad$ : Suffix of an evaluation standard of easiness of developed concepts

Before the evaluation of the developed concepts, expectations are formed as shown in Table 1. In the expectations, the evaluation of the usefulness of the concepts for early sub-operations, such as standing in front of two switches or selecting a switch, is high because the original purpose of a visual management tool is for early detection of the abnormal situation. The evaluation of the easiness of two concepts (b. prediction and c. differentiation) is high because the cost to install them is low. 
Table 1. Expectations of evaluation of the developed concepts

\begin{tabular}{|c|c|c|c|c|}
\hline Concepts & Usefulness & & Easiness & \\
\hline a. Reflection & $\begin{array}{l}\text { A worker can remember the state } \\
\text { after the operation by this concept. }\end{array}$ & High & $\begin{array}{l}\text { It is costly to prepare inferior } \\
\text { product. }\end{array}$ & Middle \\
\hline b. Prediction & $\begin{array}{l}\text { A worker can remember the state } \\
\text { after the operation by this concept. }\end{array}$ & High & It does not take effort. & High \\
\hline c. Differentiation & $\begin{array}{l}\text { This concept has the possibility to } \\
\text { not entirely remove the problem } \\
\text { of the similarity. }\end{array}$ & Middle & It does not take effort. & High \\
\hline d. Unification & $\begin{array}{l}\text { It is possible for a worker to } \\
\text { become familiar with this concept. }\end{array}$ & Middle & $\begin{array}{l}\text { It is necessary to improve the } \\
\text { relevant system. }\end{array}$ & Low \\
\hline e. Procedure & $\begin{array}{l}\text { It is possible for a worker to } \\
\text { become familiar with this concept. }\end{array}$ & Middle & $\begin{array}{l}\text { It is necessary to improve the } \\
\text { relevant system. }\end{array}$ & Low \\
\hline f. Double-check & $\begin{array}{l}\text { It is possible for a worker to } \\
\text { become familiar with this concept. }\end{array}$ & Middle & $\begin{array}{l}\text { It is necessary to improve the } \\
\text { relevant system. }\end{array}$ & Low \\
\hline g. Post-confirmation & $\begin{array}{l}\text { This concept is a countermeasure } \\
\text { after the fact. }\end{array}$ & Middle & $\begin{array}{l}\text { It is necessary to improve the } \\
\text { relevant system }\end{array}$ & Low \\
\hline
\end{tabular}

Five evaluators of the company in this case included the plant director, the head of the production division, and three experts of the total productive maintenance and management (TPM), which is one of the well-known lean management schemes. They are respectively denoted as A, B, C, D, and E in the evaluation. Based on the evaluation results presented in Tables 2 to 5, Figure 7 shows the usefulness and easiness of the seven developed concepts. The relationship between the two viewpoints is considered a trade-off relationship. Based on discussions with the evaluators, the company often uses visual management tools followed by the f. double-check concept, which is well balanced from two viewpoints. In spite of only one case, the analyzed results suggested that practitioners have developed a visual management tool using effective concepts.

Table 2. Evaluation results of usefulness of the developed concepts

\begin{tabular}{lcccccccccc}
\hline \multirow{2}{*}{ Concepts } & \multicolumn{3}{c}{$\begin{array}{c}\text { The expectation to prevent } \\
\text { accidental operation by the } \\
\text { developed concept }\end{array}$} & \multicolumn{4}{c}{$\begin{array}{c}\text { The durability of the effect } \\
\text { of the developed concept }\end{array}$} \\
\cline { 2 - 11 } & A & B & C & D & E & A & B & C & D & E \\
\hline a. Reflection & 3 & 3 & 2 & 1 & 3 & 2 & 2 & 1 & 1 & 2 \\
b. Prediction & 3 & 3 & 4 & 1 & 3 & 2 & 2 & 2 & 1 & 2 \\
c. Differentiation & 4 & 3 & 3 & 3 & 4 & 2 & 3 & 3 & 3 & 3 \\
d. Unification & 4 & 5 & 5 & 5 & 4 & 4 & 3 & 4 & 5 & 3 \\
e. Procedure & 5 & 5 & 4 & 4 & 5 & 5 & 5 & 5 & 4 & 5 \\
f. Double-check & 4 & 4 & 4 & 2 & 5 & 4 & 4 & 4 & 2 & 5 \\
g. Post-confirmation & 5 & 1 & 4 & 5 & 3 & 5 & 1 & 5 & 5 & 3 \\
\hline
\end{tabular}

5: Very high evaluation from each evaluation standard of usefulness of each concept

4: High evaluation from each evaluation standard of usefulness of each concept

3: Middle evaluation from each evaluation standard of usefulness of each concept

2: Low evaluation from each evaluation standard of usefulness of each concept

1: Very low evaluation from each evaluation standard of usefulness of each concept

Table 3. Evaluation results of easiness of the developed concepts

\begin{tabular}{|c|c|c|c|c|c|c|c|c|c|c|}
\hline \multirow[t]{2}{*}{ Concepts } & \multicolumn{5}{|c|}{$\begin{array}{l}\text { The expectation to prevent } \\
\text { accidental operation by the } \\
\text { developed concept }\end{array}$} & \multicolumn{5}{|c|}{$\begin{array}{l}\text { The durability of the effect } \\
\text { of the developed concept }\end{array}$} \\
\hline & A & $\mathrm{B}$ & $\mathrm{C}$ & $\mathrm{D}$ & $\mathrm{E}$ & $\mathrm{A}$ & $\mathrm{B}$ & $\mathrm{C}$ & $\mathrm{D}$ & $\mathrm{E}$ \\
\hline a. Reflection & 5 & 5 & 5 & 5 & 5 & 2 & 5 & 5 & 5 & 2 \\
\hline b. Prediction & 4 & 5 & 4 & 5 & 5 & 3 & 5 & 4 & 3 & 3 \\
\hline c. Differentiation & 4 & 5 & 4 & 5 & 5 & 3 & 4 & 5 & 5 & 4 \\
\hline d. Unification & 3 & 2 & 2 & 3 & 3 & 4 & 2 & 3 & 3 & 3 \\
\hline e. Procedure & 2 & 1 & 2 & 2 & 2 & 4 & 1 & 2 & 2 & 5 \\
\hline f. Double-check & 2 & 2 & 1 & 4 & 2 & 5 & 2 & 1 & 3 & 5 \\
\hline g. Post-confirmation & 1 & 1 & 1 & 1 & 2 & 5 & 1 & 1 & 1 & 3 \\
\hline
\end{tabular}

5: Very high evaluation from each evaluation standard of easiness of each concept

4: High evaluation from each evaluation standard of easiness of each concept

3: Middle evaluation from each evaluation standard of easiness of each concept

2: Low evaluation from each evaluation standard of easiness of each concept

1: Very low evaluation from each evaluation standard of easiness of each concept 
Table 4. Evaluation results of weight of usefulness and easiness of the developed concepts

\begin{tabular}{llllll}
\hline Evaluation standard & A & B & C & D & E \\
\hline The expectation to prevent accidental operation by developed concept & 3 & 5 & 5 & 4 & 5 \\
The durability of the effect of developed concept & 4 & 5 & 4 & 3 & 3 \\
The development economics of developed concept & 5 & 3 & 3 & 3 & 4 \\
The reconstruction degree of the installation place of developed concept & 4 & 5 & 3 & 4 & 5 \\
\hline
\end{tabular}

5: Very high evaluation from each evaluation standard

4: High evaluation from each evaluation standard

3: Middle evaluation from each evaluation standard

2: Low evaluation from each evaluation standard

1: Very low evaluation from each evaluation standard

Table 5. Calculation results of usefulness and easiness of the developed concepts

\begin{tabular}{lcccccccccc}
\hline \multirow{2}{*}{ Concepts } & \multicolumn{4}{c}{$e 1_{h}$ (after standardization) } & \multicolumn{4}{c}{$e 2_{h}$ (after standardization) } \\
\cline { 2 - 12 } & A & B & C & D & E & A & B & C & D & E \\
\hline a. Reflection & 1.7 & 2.5 & 1.4 & 0.7 & 2.1 & 3.3 & 4.0 & 3.0 & 3.5 & 3.0 \\
b. Prediction & 1.7 & 2.5 & 2.8 & 0.7 & 2.1 & 3.2 & 4.0 & 2.4 & 2.7 & 3.5 \\
c. Differentiation & 2.0 & 3.0 & 2.7 & 2.1 & 2.9 & 3.2 & 3.5 & 2.7 & 3.5 & 4.0 \\
d. Unification & 2.8 & 4.0 & 4.1 & 3.5 & 2.9 & 3.1 & 1.6 & 1.5 & 2.1 & 2.7 \\
e. Procedure & 3.5 & 5.0 & 4.0 & 2.8 & 4.0 & 2.6 & 0.8 & 1.2 & 1.4 & 3.3 \\
f. Double-check & 2.8 & 4.0 & 3.6 & 1.4 & 4.0 & 3.0 & 1.6 & 0.6 & 2.4 & 3.3 \\
g. Post-confirmation & 3.5 & 1.0 & 4.0 & 3.5 & 2.4 & 2.5 & 0.8 & 0.6 & 0.7 & 2.3 \\
\hline
\end{tabular}

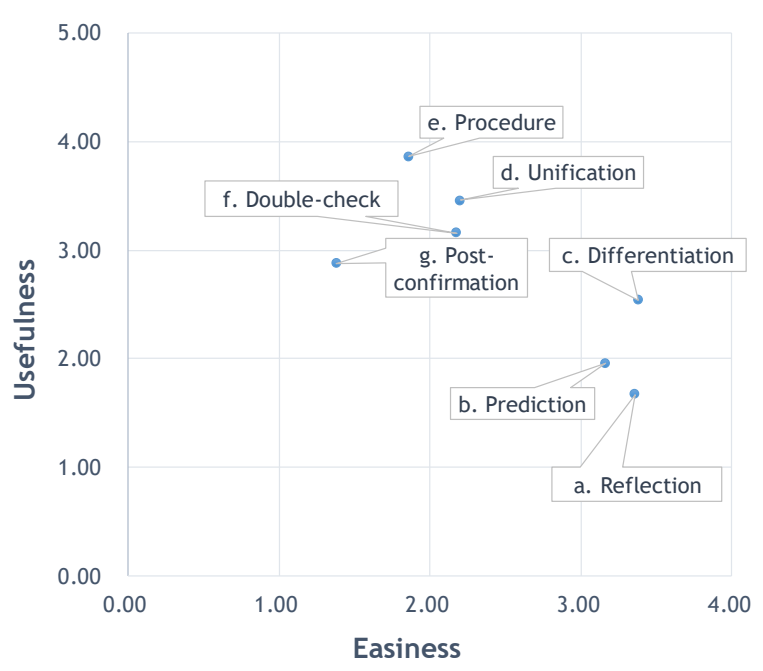

Figure 7. Usefulness and easiness of the seven developed concepts (average of five evaluators).

\section{DISCUSSION}

This section discusses the results from Section 5 on the basis of two key items: 1) a reaction function from people to a production system; and 2) functions of a tool from a production system to people. This discussion is further based on the proposed framework in Section 4.

\section{Required concepts of developed tools}

Table 6 shows the comparison between the expectation of evaluation of the developed concepts and the results. For comparison, the obtained scores are classified by the standard divided equally among three (see notes in Table 6). Remarkably, the evaluation results of the usefulness of a. reflection and b. prediction were lower than their expectations. Further, the evaluation results of the usefulness of e. procedure were higher than their expectations. The analyzed results indicate that concepts "just before" the operation are important compared with that of concepts "before" the operation. A conventional idea of a visual management tool is for early detection of an abnormal situation. However, the necessary visual management tool for a countermeasure depends on the circumstances. The results indicate that it is necessary to consider the capability of comprehensibility of a visual management tool when designing a reaction function requested by a production system from people. 
Table 6. Comparison between expectations and results of evaluation of the developed concepts

\begin{tabular}{lcccc}
\hline \multirow{2}{*}{ Concepts } & \multicolumn{2}{c}{ Usefulness } & \multicolumn{2}{c}{ Easiness } \\
\cline { 2 - 5 } & Expectation & Result & Expectation & Result \\
\hline a. Reflection & High & Low & Middle & Middle \\
b. Prediction & High & Low & High & Middle \\
c. Differentiation & Middle & Middle & High & Middle \\
d. Unification & Middle & Middle & Low & Low \\
e. Procedure & Middle & High & Low & Low \\
f. Double-check & Middle & Middle & Low & Low \\
g. Post-confirmation & Middle & Middle & Low & Low \\
\hline
\end{tabular}

\section{Required functions of developed tools}

As previously discussed in Section 5.2, the development to resolve the twin-switch problem consists of four steps: 1) analyze the processes of the target operation; 2) consider the visualized item for each analyzed process; 3) conceptualize the tool for each visualized item; and 4) design a tool for each visualized item. These are divided into two transactions: the first represents the first sub-function of the proposed framework, which is a creation of information from a production system to a tool; and the second represents the second sub-function of the proposed framework, which is a transformation of information from a tool to people. In order to realize the totality of development of a visual management tool, this systematic procedure should be considered, following the proposed framework.

Additionally, there were two capabilities of each sub-function, respectively. The capabilities of the first sub-function were non-ordinariness and continuity. The capabilities of the second sub-function were inducibility and timeliness.

Non-ordinariness is included in all seven concepts as the capability of the tool. However, the level of the problemsolving process varies among them. The early concepts, such as a. reflection and b. prediction, must advance the predetection of an abnormal situation of a production system. The later concepts, such as g. post-confirmation, visualize the transactions after the occurrence of an abnormal situation in a production system. The choice of concepts may follow the management level of a production system. Perhaps the installation of a combination with some concepts by all levels of problem-solving may be an effective method to operate a production system without trouble.

As for continuity in the twin-switch problem, monitoring the time the abnormal situation occurs is difficult because miss-switching directly causes the miss-operation of a production system. However, the seven concepts support operations both before and after such an incident occurs. The detection function of the situation of the seven concepts are divided into two types. One type is the function to inform the existence of the possibility of miss-operation by various icons (i.e., a sensor, a picture, color, and sound). The concepts that fall under this type include: a. reflection, b. prediction, c. differentiation, f. double-check, and g. post-confirmation. The other types are the functions to inform the correct switch operation by deleting latent abnormal situations with Poka-Yoke systems (Vinod et al., 2017). The concepts that fall under this type include: $d$. unification and e. procedure.

The tool without the capability of inducibility becomes the "background" of a production activity, which means that soon after installation, nobody notices it. The linkage of a tool's operation with a switch's operation is considered to be one of the most effective measures to maintain the capability. Concepts that fall under this viewpoint include: e. procedure and f. double-check.

With regard to timeliness, a. reflection, b. prediction, and c. differentiation are relevant concepts because an abnormal situation is recognized before the occurrence of a miss-operation.

The above-mentioned development of the concept to solve the 'twin-switch problem' was performed independently from the proposed framework. And then, the discussion involving the proposed framework contributes to understanding the steps of the concept development as a systematic approach, and to clarify the capability of each concept. Many practitioners can utilize the proposed framework to strengthen their countermeasure to the 'twin-switch problem' because the problem occurs in many chemical plants. Based on the above result, the initial utility of the proposed framework can be confirmed.

For the limitation, the two switch problem picked up in this paper is just one case. The wider range of application to other manufacturing sector or other industries of the proposed framework should be proven in the future. Also the analysis of various types of visual management systems should be carried out using the block diagram from control theory. These will lead to deeper insight on the mechanisms of a visual management tool as the theoretical study. Furthermore, the possibility of a scientific analysis of other lean management tools can be expected to grow. Control theory, which is applied to the proposed framework, has probably a wider range of application. For example, the theoretical interpretation of a visual management system may support the evaluation of the function by a numerical experiment on the basis of mathematical modelling and computer simulation.

\section{CONCLUDING REMARKS}

The proposed framework can provide insights on the internal mechanisms of a visual management system through common perspectives. In the discussion of the development case in Section 6, not only the robust evaluation of individual concepts of the tool, but also a systematic comparison among seven concepts could be realized through the proposed 
framework, including the two key functions with the five capabilities. Such a new approach leads to strengthening of the theoretical study of visual management, given that practical studies mainly provide good applications and guidance to install/perform visual management schemes in the main fields of study, such as operations management and lean management. Moreover, the proposed framework contributes to understanding visual management systems more systematically than what is allowed by Womack et al. (2003)'s definition and many relevant concepts such as visual factory (Greif, 1991), visual communication (Mestre et al., 2000), and visual workplace (Galsworth, 1997). And then, the theoretical study of visual management should be continually strengthened from various perspectives, such as organizational barriers and organizational psychology, as indicated in Bell et al. (2013) and Tezel et al. (2016) in section 2.

Practitioners may utilize the proposed framework to develop a visual management system. The conventional approach centers on the development of an elemental technique, such as a sensor, a picture, and color coordinates. It is concerned with only one of the two tool functions of the proposed framework, namely the transmission of information from the tool to people. However, a correct design of the visualized item from the viewpoint of the other tool function, the creation of information from the production system to the tool, is also important, for ensuring an appropriate outcome from a visual management system.

\section{REFERENCES}

Abou-Ibrahim, H., \& Hamzeh, F. (2020). A visual dashboard to monitor BIM model dynamics. Canadian Journal of Civil Engineering, 47(2), 178-185.

Barenji, R. V., Barenji, A. V., \& Hashemipour, M. (2014). A multi-agent RFID-enabled distributed control system for a flexible manufacturing shop. The International Journal of Advanced Manufacturing Technology, 71(9-12), 1773-1791.

Bell, E., \& Davison, J. (2013). Visual management studies: Empirical and theoretical approaches. International Journal of Management Reviews, 15(2), 167-184.

Beynon-Davies, P., \& Lederman, R. (2017). Making sense of visual management through affordance theory. Production Planning \& Control, 28(2), 142-157.

Brady, D. A., Tzortzopoulos, P., Rooke, J., Formoso, C. T., \& Tezel, A. (2018). Improving transparency in construction management: a visual planning and control model. Engineering, Construction and Architectural Management, 10(15), 1277-1297.

Cahyadi, A., Ruslan, W., \& Sukwadi, R. (2020). Quality Shop Floor Management Based on Abnormality Management. International Journal of Applied Engineering Research, 15(6), 550-556.

Carbonara, N., \& Pellegrino, R. (2017). How do supply chain risk management flexibility-driven strategies perform in mitigating supply disruption risks?. International Journal of Integrated Supply Management, 11(4), 354-379.

Carver, C. S., \& Scheier, M. F. (1982). Control theory: A useful conceptual framework for personality-social, clinical, and health psychology. Psychological bulletin, 92(1), 111-135.

Chen, C. W. (2020). Internet of Video Things: Next-Generation IoT With Visual Sensors. IEEE Internet of Things Journal, 7(8), 66766685 .

De Jong, T., \& Ferguson-Hessler, M. G. (1996). Types and qualities of knowledge. Educational psychologist, 31(2), 105-113.

Del Vecchio, D., Dy, A. J., \& Qian, Y. (2016). Control theory meets synthetic biology. Journal of The Royal Society Interface, 13(120), https://doi.org/10.1098/rsif.2016.0380.

Dolgui, A., Ivanov, D., \& Sokolov, B. (2018). Ripple effect in the supply chain: an analysis and recent literature. International Journal of Production Research, 56(1-2), 414-430.

Dumitrascu, O., Dumitrascu, M., \& Dobrotă, D. (2020). Performance Evaluation for a Sustainable Supply Chain Management System in the Automotive Industry Using Artificial Intelligence. Processes, 8(11), 1384, doi:10.3390/pr8111384.

Eaidgah, Y., Maki, A. A., Kurczewski, K., \& Abdekhodaee, A. (2016). Visual management, performance management and continuous improvement. International Journal of Lean Six Sigma, 7(2), 187-210.

Edghill, J., \& Towill, D. (1989). The use of system dynamics in manufacturing systems engineering. Transactions of the Institute of Measurement and Control, 11(4), 208-216.

Fitrianie, S., \& Rothkrantz, L. J. (2007). A visual communication language for crisis management. Int. Journal of Intelligent Control and Systems (Special Issue of Distributed Intelligent Systems), 12(2), 208-216.

Fonseca, L. M. (2017). In search of six sigma in portuguese SMEs. International Journal of Industrial Engineering and Management, 8(2017), 31-38.

Flumerfelt, S., Calvo-Amodio, J., \& Porter, J. D. (2017). Tapping the potential of sensemaking for performance management. Measuring Business Excellence, 21(3), 214-224.

Galsworth, G. D. (1997). Visual systems: harnessing the power of the visual workplace (p. 320). New York: American Management Association.

Greif, M. (1991). The visual factory: building participation through shared information. CRC Press.

Hohenstein, N. O., Feisel, E., Hartmann, E., \& Giunipero, L. (2015). Research on the phenomenon of supply chain resilience. International Journal of Physical Distribution \& Logistics Management, 45(1/2), 90-117.

Holmström, J., Ketokivi, M., \& Hameri, A. P. (2009). Bridging practice and theory: A design science approach. Decision Sciences, 40(1), 65-87.

Hozak, K., \& Olsen, E. O. (2015). Lean psychology and the theories of “Thinking, Fast and Slow". International Journal of Lean Six Sigma, 6(3), 206-225.

Iqbal, S., Qureshi, S. A., Rizvi, T. H., Abbas, G., \& Gulzar, M. M. (2010). Concept building through block diagram using matlab/simulink. IEEEP Journal, 66, 67, 30-34.

Isack, H. D., Mutingi, M., Kandjeke, H., Vashishth, A., \& Chakraborty, A. (2018). Exploring the adoption of Lean principles in medical laboratory industry. International journal of lean six sigma, 9(1), 133-155.

Istanbulluoglu, D. (2017). Complaint handling on social media: The impact of multiple response times on consumer satisfaction. Computers in Human Behavior, 74, 72-82. 
Ivanov, D., Dolgui, A., \& Sokolov, B. (2012). Applicability of optimal control theory to adaptive supply chain planning and scheduling. Annual Reviews in control, 36(1), 73-84.

Jadhav, J. R., Mantha, S. S., \& Rane, S. B. (2014). Exploring barriers in lean implementation. International Journal of Lean Six Sigma, $5(2), 122-148$

Koren, Y. (2010). The global manufacturing revolution: product-process-business integration and reconfigurable systems (Vol. 80). John Wiley \& Sons.

Liker, J. (2004). The Toyota Way: 14 Management Principles from the World's Greatest Manufacturer, McGraw-Hill Education.

Laoha, C., \& Sukto, S. (2016). Opportunities for improvement in five groups of SMEs by a new lean assessment tool. Engineering and Applied Science Research, 43, 342-345.

Mestre, M., Stainer, A., Stainer, L., \& Strom, B. (2000). Visual communications-the Japanese experience. Corporate Communications: An International Journal, 5(1), 34-41.

Murata, K., \& Katayama, H. (2008). Study on taxonomy of visual management technology for Effective Technology Transfer. Journal of the Society of Plant Engineer Japan, 19(4), 8-13 (in Japanese).

Murata, K., \& Katayama, H. (2010a). Development of Kaizen case-base for effective technology transfer-a case of visual management technology. International Journal of Production Research, 48(16), 4901-4917.

Murata, K., \& Katayama, H. (2010b). A study on construction of a kaizen case-base and its utilisation: a case of visual management in fabrication and assembly shop-floors. International Journal of Production Research, 48(24), 7265-7287.

Murata, K., \& Katayama, H. (2013). A study of the performance evaluation of the visual management case-base: development of an integrated model by quantification theory category III and AHP. International Journal of Production Research, 51(2), $380-394$.

Murata, K., \& Katayama, H. (2016). Performance evaluation of a visual management system for effective case transfer. International Journal of Production Research, 54(10), 2907-2921.

Ohno, T. (1988). Toyota production system: beyond large-scale production. CRC Press.

Oliva, S., \& Lazzeretti, L. (2018). Measuring the economic resilience of natural disasters: An analysis of major earthquakes in Japan. City, culture and society, 15, 53-59.

Ortega, M., \& Lin, L. (2004). Control theory applications to the production-inventory problem: a review. International Journal of Production Research, 42(11), 2303-2322.

Paro, P. E. P., \& Gerolamo, M. C. (2017). Organizational culture for lean programs. Journal of Organizational Change Management, 30(4), 584-598.

Parry, G. C., \& Turner, C. E. (2006). Application of lean visual process management tools. Production planning \& control, 17(1), 7786.

Pató, B. S. G. (2017). Formal options for job descriptions: theory meets practice. Journal of Management Development, 36(8), 10081028 .

Rees, G., Russell, C., Frith, C. D., \& Driver, J. (1999). Inattentional blindness versus inattentional amnesia for fixated but ignored words. Science, 286(5449), 2504-2507.

Sacks, R., Koskela, L., Dave, B. A., \& Owen, R. (2010). Interaction of lean and building information modeling in construction. Journal of construction engineering and management, 136(9), 968-980.

Scupin, R. (1997). The KJ method: A technique for analyzing data derived from Japanese ethnology. Human organization, 56(2), 233237.

Simon, H. A. (1952). On the application of servomechanism theory in the study of production control. Econometrica: Journal of the Econometric Society, 247-268.

Simons, D. J., \& Levin, D. T. (1998). Failure to detect changes to people during a real-world interaction. Psychonomic Bulletin \& Review, 5(4), 644-649.

Simons, D. J., \& Chabris, C. F. (1999). Gorillas in our midst: Sustained inattentional blindness for dynamic events. perception, 28(9), 1059-1074.

Singh, S., \& Kumar, K. (2020). A study of lean construction and visual management tools through cluster analysis. Ain Shams Engineering Journal, https://doi.org/10.1016/j.asej.2020.04.019.

Sisson, J., \& Elshennawy, A. (2015). Achieving success with Lean: An analysis of key factors in Lean transformation at Toyota and beyond. International Journal of Lean six sigma, 6(3), 263-280.

Spear, S., \& Bowen, H. K. (1999). Decoding the DNA of the Toyota production system. Harvard business review, 77, 96-108.

Steenkamp, L. P., Hagedorn-Hansen, D., \& Oosthuizen, G. A. (2017). Visual management system to manage manufacturing resources. Procedia Manufacturing, 8, 455-462.

Stefik, M., \& Stefik, B. (2004). Breakthrough: stories and strategies of radical innovation. MIT press.

Spiegler, V. L., \& Naim, M. M. (2017). Investigating sustained oscillations in nonlinear production and inventory control models. European Journal of Operational Research, 261(2), 572-583.

Subramanian, K., Rawlings, J. B., Maravelias, C. T., Flores-Cerrillo, J., \& Megan, L. (2013). Integration of control theory and scheduling methods for supply chain management. Computers \& Chemical Engineering, 51, 4-20.

Sugawara, S., Suzuki, G., Nagashima, Y., Matsuura, M., Tanigawa, H., \& Moriuchi, M. (1994). InterSpace: Networked virtual world for visual communication. IEICE transactions on information and systems, 77(12), 1344-1349.

Tervo, K., Palmroth, L., \& Koivo, H. (2009). Skill evaluation of human operators in partly automated mobile working machines. IEEE Transactions on automation science and engineering, 7(1), 133-142.

Tezel, A., Koskela, L., \& Tzortzopoulos, P. (2016). Visual management in production management: a literature synthesis. Journal of manufacturing technology management, 27(6), 766-799.

Tezel, A., \& Aziz, Z. (2017a). Visual management in highways construction and maintenance in England. Engineering, Construction and Architectural Management, 24(3), 486-513.

Tezel, B. A., \& Aziz, Z. (2017b). From conventional to IT based visual management: a conceptual discussion for lean construction. Journal of information technology in construction, 22, 220-246.

Tezel, A., Koskela, L., \& Aziz, Z. (2018). Lean thinking in the highways construction sector: motivation, implementation and barriers. Production Planning \& Control, 29(3), 247-269.

Tjell, J., \& Bosch-Sijtsema, P. M. (2015). Visual management in mid-sized construction design projects. Procedia Economics and Finance, 21, 193-200. 
Valente, C., Brandalise, F., Pivatto, M., \& Formoso, C. (2017). Guidelines for Devising and Assessing Visual Management Systems in Construction Sites. In LC3 2017 Volume II-Proceedings of the 25th Annual Conference of the International Group for Lean Construction (IGLC) (pp. 703-710). Heraklion, Greece.

Verbano, C., Crema, M., \& Nicosia, F. (2017). Visual management system to improve care planning and controlling: the case of intensive care unit. Production Planning \& Control, 28(15), 1212-1222.

Verner, L., Oleynikov, D., Holtmann, S., Haider, H., \& Zhukov, L. (2003). Measurements of the level of surgical expertise using flight path analysis from da Vinci robotic surgical system, Stud Health Technol Inform, 94, 373-378.

Vinod, M., Devadasan, S. R., Sunil, D. T., Thilak, V. M. M., \& Murugesh, R. (2017). POYSS: a model for integrating Poka-Yoke technique with Six Sigma concept. International Journal of Productivity and Quality Management, 22(2), 223-242.

Wang, Z., Liao, M., Hagihara, R., \& Maekawa, Z. (2015). Comparison between Expert and Beginner on Calligraphy Letter's Characteristic. Procedia Manufacturing, 3, 495-502.

Wu, Z., Liu, G. P., \& Chen, D. (2020). Advertising strategies and coordination for supply chain based on consignment platform with delayed effect. Systems Science \& Control Engineering, 8(1), 162-174.

Womack, J. P., \& Jones, T. D. (2003). Lean Thinking: Banish Waste and Create Wealth in your Corporation, Free Press, New York, NY.

Zia, A., Sharma, Y., Bettadapura, V., Sarin, E. L., \& Essa, I. (2018). Video and accelerometer-based motion analysis for automated surgical skills assessment. International journal of computer assisted radiology and surgery, 13(3), 443-455.

Zhou, B. (2016). Lean principles, practices, and impacts: a study on small and medium-sized enterprises (SMEs). Annals of Operations Research, 241(1-2), 457-474.

Zsidisin, G. A., Melnyk, S. A., \& Ragatz, G. L. (2005). An institutional theory perspective of business continuity planning for purchasing and supply management. International journal of production research, 43(16), 3401-3420.

\section{ACKNOWLEDGEMENT}

The members of Innovative Design Lab., University of Huddersfield, Dr. Algan Tezel, Prof. Lauri Koskela \& Prof. Patricia Tzortzopoulos Fazenda, helped in various aspects such as exchanging opinions on this study and proofreading in English. Dr. Tanika D. Sofianti, Swiss German University, also provided the chance for the publication of this study. I would like to express my heartful gratitude for your supports.

\section{CONFLICT OF INTEREST DECLARATION}

No potential conflict of interest was reported by the authors.

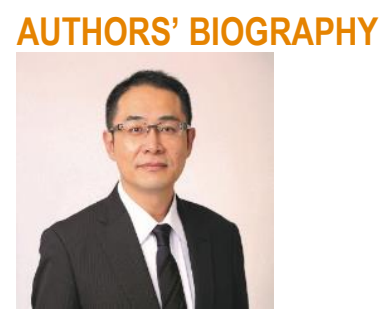

Koichi Murata is a professor of operations \& production management at Nihon University, Japan. His interests include, kaizen, lean management, visual management, knowledge management, sustainable supply chain. He has published articles in International Journal of Production Research, and Sustainability etc. He was interviewed for NHK and the Associated Press. 